FINAL REPORT DOE/ER/62847-1

11 April 2005

U.S. DEPARTMENT OF ENERGY GRANT DE-FG03-99ER62847

\title{
MULTIRESOLUTION FEATURE ANALYSIS AND OTHER TECHNIQUES FOR UNDERSTANDING AND MODELING TURBULENCE IN STABLE ATMOSPHERES
}

Cost: $\$ 565,314$

Period: 09/01/99 through 10/31/04

\author{
Investigators: R. L. Street, F. L. Ludwig and Ying Chen \\ Environmental Fluid Mechanics Laboratory \\ Department of Civil and Environmental Engineering \\ Stanford University \\ Stanford, CA 94305-4020
}

\begin{abstract}
Our DOE project is one of the efforts comprising the Vertical Transport and Mixing Program of the Environmental Sciences Division of the Office of Biological and Environmental Research in Department of Energy. We used ARPS to simulate flow in the Salt Lake Valley. We simulated the physical processes more accurately so that we can better understand the physics of flow in complex terrain and its effects at larger scales. The simulations provided evidence that atmospheric forcing interacts with the Jordan Narrows, the Traverse Range and other complex mountain terrain at the south end of the Salt Lake Valley to produce lee rotors, hydraulic jumps and other effects. While we have successfully used ARPS to simulate VTMX 2000 flows, we have also used observed data to test the model and identify some of its weaknesses. Those are being addressed in a continuation project supported by DOE.
\end{abstract}

\section{Focus of the Work}

Our DOE project is one of the efforts comprising the Vertical Transport and Mixing Program of the Environmental Sciences Division of the Office of Biological and Environmental Research in Department of Energy. That DOE work uses observations from the 2000 Vertical Transport and Mixing Experiment (VTMX) and numerical simulations to define observable patterns of atmospheric motion related to occurrences of vertical mixing in stable, urban atmospheres, especially in regions of complex topography.

We simulated the physical processes more accurately so that we can better understand the physics of flow in complex terrain and its effects at larger scales. We have been addressing the following important scientific issues:

1. Identifying and quantifying fundamental processes that control vertical transport for stable and transition boundary layers with measurements and simulations. 
2. Improving numerical simulation and prediction of momentum, heat, and moisture fluxes, and of vertical transport and mixing in a stratified atmosphere with multiple layers during stable and transition periods.

3. Quantifying the sensitivity of dispersion model predictions to vertical diffusivity, turbulence, and the thermal and roughness properties of urban areas to improve understanding of how pollutants move through residual layers above stable or convective boundary layers.

4. Determining, and quantifying, the interaction of synoptic and terrain-induced flows with cold air pools in basins, and how they affect the evolution of those pools and pollutant dispersion in them.

Considerable progress has been made in the above areas.

\section{Method}

Accurate weather prediction is critical to public safety, successful military operations, and protection of the environment from air-borne pollution. Limited area models [LAM] are used for weather research and operational prediction. They are nested in a larger domain and are forced at their lateral boundaries by simulations on the larger domain. LAM simulations can be done over domains from about $10 \mathrm{~km}$ on a side to domains as large as the Salt Lake Valley. We have used this approach here.

The Advanced Regional Prediction System [ARPS] is an unsteady, three-dimensional, non-hydrostatic, compressible, large-eddy simulation [LES] code and can be run in parallel mode using the message-passing interface [MPI]. It has generalized terrainfollowing coordinates, comprehensive physical parameterizations (radiation, surface layer behavior, heat transfer in the soil, and cloud microphysics). We have applied ARPS to the Salt Lake Valley wind system. Our results have given us a better understanding of relevant atmospheric physics. These accomplishments required state-of-the-art grid resolutions ( $\sim 100 \mathrm{~m}$ horizontal, 200 vertical levels) and a highly parallel code. ARPS has modular structure, clean and understandable codes, good scalability, comprehensive documentation and other attractive features that make it ideal for incorporating and testing our models. This new-generation, well-documented code is appropriate for LES resolutions (Xue, et al. 1995, 2000, 2001, 2003; Rao, et al., 1999; Doyle, et al., 2000; Chow and Street, 2002), and its state-of-the-art parameterizations (e.g., Chow and Street, $2002 \& 2004$, and Ren and Xue, 2004) are frequently updated and augmented. New modules can be added to treat processes not originally included (e.g., Colette, et al., 2003). We have created and validated advanced subfilter closures for ARPS (Chow and Street, $2002 \&$ 2004). Version 5.1, to which we have contributed, was released in early 2004.

Our coarsest ARPS grid is initialized and forced by external conditions from a large-scale code, (e.g., NCEP's Eta code) so we can simulate specific cases to be compared with observations. The ARPS one-way self-nesting sets boundary values for the finer grids, using a relaxation boundary condition with an extra forcing term in the RHS of the governing equations. Small-scale computational noise is suppressed with additional fourth-order computational mixing on the RHS of the conservation equations, excepting pressure. In the context set by Warner, et al. (1997), ARPS lateral boundary conditions 
do not add numerical artifacts, because they are well-posed mathematically in this nonhydrostatic and compressible code.

ARPS is a FORTRAN 90 code that solves a finite difference model for the compressible, nonhydrostatic, partial differential equations of fluid dynamics, as well as the appropriate transport equations for heat, water vapor, etc. The solution algorithms are a mode-split set, with the fast motions solved on a small time step. When the domain is decomposed for MPI or when the grids are nested or receive input from surrounding domains boundary values are exchanged at every small time step. The equations are discretized on an Arakawa C-grid and advanced in time with a leapfrog scheme for the large time step, except for scalars where a flux-corrected transport scheme is used. The advection terms are fourth-order accurate; other spatial difference terms are second-order accurate. The vertical velocity and pressure equations are handled implicitly with a Crank-Nicolson scheme.

Our runs on Seaborg [Power3] and NCAR's bluesky [Power4] were significantly faster than those previously achieved with ARPS. The paper by Oliker, et al. (2004) was insightful for our work. In the past, we have achieved 14\% efficiency on 16 processors and $11 \%$ efficiency on 64 processors at NERSC. According to our tests, the code has an

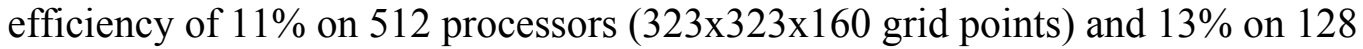
processors (195x195x80 grid points). These estimates are from the poe + utility. Our results are consistent with [and indeed better than] the Oliker, et al., results for codes like ARPS. On reviewing our code description, Dr. Oliker's opinion [August 2004] was "if your code is achieving between $10-15 \%$ on NERSC, I would say that is relatively high performance, we generally see less than $10 \%$ for codes (other than BLAS3 based calculations) - additionally if your code is performing boundary communication after each time step, then it would not be surprising if you incurred a high communication overhead."

\section{Results}

During the course of this project, we have assembled a comprehensive data base including most of the data collected during the VTMX 2000 campaign (Doran et al, 2002); we have modified objective analysis computer codes to make effective use of the variety of data collected (Ludwig et al. 2002a), and we developed new classification approaches (Ludwig et al. 2002b \& 2003) based on empirical orthogonal functions (EOF). We have also distributed CD-ROMs containing routine meteorological and special field project data. The special VTMX 2000 data have proven exceedingly valuable in our studies.

Our DOE VTMX project used ARPS to simulate flow in the Salt Lake Valley. The simulations provided evidence that atmospheric forcing interacts with the Jordan Narrows, the Traverse Range and other complex mountain terrain at the south end of the Salt Lake Valley to produce lee rotors, hydraulic jumps and other effects (Chen, et al., 2004a). We used six one-way, nested grids from $20-\mathrm{km}$ spacing (initialized by Eta $40-$ $\mathrm{km}$ operational analyses) down to $250-\mathrm{m}$. The finest vertical resolution had 200 stretched vertical levels (up to $20 \mathrm{~km}$ ) beginning with a $10-\mathrm{m}$ cell at the surface. Simulations of 
two stably stratified days with weak synoptic winds, and pronounced nighttime drainage reproduced recorded wind and temperature structures (including inversion strength and depth) at four observation sites. Agreement was always good qualitatively, and usually quantitatively as well. As noted, simulated flow near the Jordan Narrows is quite complex with rotors, hydraulic jumps, and internal waves induced by flow over the Traverse Range (see http://www.stanford. edu/ yingchen/ and Chen, et al., 2002 \& 2004a $\& b)$.

We simulated weakly forced up-valley and down-valley daytime and nighttime flows in the Salt Lake Valley to see if they were similar to flows in other mountain regions. Zhong and Fast (2003) examined model performance for similar conditions in the same area, testing MM5, the Regional Atmospheric Modeling System (RAMS, Pielke, et al. 1992) and the Meso Eta model (Black, 1994 and Mesinger, et al. 1990). They used five MM5 and RAMS nested grids (down to $560 \mathrm{~m}$ ), and one (about $850 \mathrm{~m}$ ) Meso Eta grid (it has no nesting provision), and found that nested models captured slope, canyon and valley flows better than Meso Eta, but none did well with weak nocturnal inversions. All models had a cold temperature bias at all levels and erred significantly in jet structure. Benoit, et al. (2002) state that 1-km horizontal resolution is needed to resolve intense gravity waves in a mountainous area, but Zhong and Fast (2003) failed to find all observed flow features even at their finer resolutions $(\geq 560 \mathrm{~m})$, suggesting a need for still finer resolution.

Jiang and Doyle (2003) comment that, "Mountain-wave breaking has an important influence on the atmosphere for several reasons. The vertical momentum flux associated with wave breaking and orographic drag has a profound impact on the atmospheric general circulation. Downslope windstorms and drag enhancement may occur as a result of resonant mountain-wave amplification ... Large vertical diffusivity associated with the turbulent breakdown of orographically generated gravity waves results in efficient mixing of water vapor, aerosols, various chemical species, and trace gases. . " It is clear that these events also have effects at scales larger than the sizes of the features themselves. Doyle, et al. (2000) and our own work have shown that ARPS reproduces the effects that we study when the resolution is fine enough and appropriate turbulence and surface layer models are used. Chen, et al. (2004a) showed that rotors form in the lee of both the east and west sections of the Traverse Range in the Salt Lake Valley. Doyle and Durran (2003) and Grubišić and Kuettner (2004) attest to the need for better understanding of these potentially dangerous features.

\section{Continuation}

We have successfully used ARPS to simulate VTMX 2000 flows, and used observed data to test the model and identify some of its weaknesses (Chen et al, 2004a). We have identified and corrected several problems related to spatial resolution, but still need to make further modifications. This work has been continued under an extension grant: DEFG02-04ER63705 with a cost of \$ 130,384 and period from 11/01/03 through 10/31/05.

Other factors required for successful simulations are the proper grid aspect ratio and a good representation of near ground effects. We have obtained realistic results with 
horizontal resolutions of $250 \mathrm{~m}$ and vertical resolutions of $10 \mathrm{~m}$ near the surface. The finer resolution in the model will require more detailed characterization of surface properties. The U. S. Geological Survey (USGS) provides terrain elevation data files with horizontal resolution of $100 \mathrm{~m}$, which we already use. The 1992 USGS National Land Cover Data (NLCD) has 30-m resolution, and categorizes land cover over the United States into one of 21 categories (e. g., Open Water, Low and High density Residential, Mixed Forest, Pasture, Fallow and so forth), thus allowing us to derive the 30-m resolution vegetation types, vegetation fractions and surface roughness lengths that are required by ARPS. However, the data sets do not include sufficient soil type information so we may have to rely on $1-\mathrm{km}$ soil data. We will merge the information from the above data sets and others that provide, e.g., leaf area index, to create a comprehensive Salt Lake Valley data set that will allow us to complete our simulations.

\section{Publications supported by this grant}

Chen, Y., Street, R. and Ludwig, F. (2002) Numerical modeling of airflow in the vicinity of the Jordan Narrows in the Salt Lake Valley, 10th Conf. Mountain Meteorol., AMS., pp. 39-41.

Chen, Y., Ludwig, F. L., \& Street, R. L. (2004a) Stably-stratified flows near a notched, transverse ridge across the Salt Lake Valley, Journal of Applied Meteorology, AMS, 43, pp. 1308-1328.

Chen, Y., Street, R. L., and Ludwig, F. L. (2004b) On rotors, internal waves and hydraulic jumps in simulated stably-stratified flows in Utah's Salt Lake valley, $11^{\text {th }}$ Mountain Meteorology Conference, AMS, Paper P1.2, 5 pages.

Ludwig, F. L., Y. Chen, R. L. Street, 2002a: Integration of data from many sources for objective analysis of three-dimensional meteorological fields in the Salt Lake City Area, preprints 4th Symp. Urban Environ., Amer. Meteorol. Soc., Boston, pp 178-179.

Ludwig, F. L., R. Street, and Y. Chen, 2002b: Detection and interpretation of patterns of motion in mesoscale atmospheric flows, Eos, AGU Fall Meeting and Abstracts, CD, A51C-0068.

Ludwig, F. L., J. Horel, C. D. Whiteman, 2003: Using EOF analysis to identify important surface wind patterns in mountain valleys, J. Appl. Meteorol., 43, pp. 969-83.

\section{References}

Benoit, R., Schar, C., Chamberland, S., Davies, H.C., Desgagne, M., Girard, C., Keil, C., Luthi, D., Maric, D., Muller, E., Pellerin, P., Schubiger, F., Schwierz, C., Sprenger, M., Walser, A., Willemse, S., Yu, W., and Zala, E. (2002) The real-time ultrafinescale forecast support during the special observing period of the MAP, Bull. Amer. Meteor. Soc., 83, pp. 85-109.

Black, T. L. (1994) The new NMC mesoscale Eta model: description and forecast examples, Wea. and Forecast, 9, pp. 265-284.

Chen, Y., Street, R. and Ludwig, F. (2002) Numerical modeling of airflow in the vicinity of the Jordan Narrows in the Salt Lake Valley, 10th Conf. Mountain Meteorol., AMS., pp. 39-41.

Chen, Y., Ludwig, F. L., \& Street, R. L. (2004a) Stably-stratified flows near a notched, transverse ridge across the Salt Lake Valley, Journal of Applied Meteorology, AMS, 43, pp. 1308-1328. 
Chen, Y., Street, R. L., and Ludwig, F. L. (2004b) On rotors, internal waves and hydraulic jumps in simulated stably-stratified flows in Utah's Salt Lake valley, $11^{\text {th }}$ Mountain Meteorology Conference, AMS, Paper P1.2, 5 pages.

Chow, F. K., \& Street, R. L. (2002) Modeling unresolved motions in LES of field-scale flows, $15^{\text {th }}$ Symposium on Boundary Layers and Turbulence, AMS, Paper 9.5, pp. 432 -435 .

Chow, F. K., \& Street, R. L. (2004) Explicit filtering and reconstruction turbulence modeling for large-eddy simulations of field-scale flows, Advances in Hydro-Science and -Engineering [Proc. $6^{\text {th }}$ International Conference on Hydroscience and Engineering, Brisbane, Aus.], Vol. VI, CD-ROM, Paper Locator No. =432, 12 pages [Invited].

Colette, A., Chow, F. K., \& Street, R. L. (2003) A numerical study of inversion layer breakup and the effects of topographic shading in idealized valleys, Journal of Applied Meteorology, AMS, 42 (9), pp. 1255-1272.

Doran, J. C., J. D. Fast, and J. Horel, 2002: The VTMX 2000 campaign, Bull. Amer. Meteor. Soc., 83, 537-551.

Doyle, J. D., Durran, D. R., Chen, C., Colle, B. A., Georgelin, M., Grubisic, V., Hsu, W. R., Huang, C. Y., Landau, D., Lin, Y. L. (2000) An intercomparison of modelpredicted wave breaking for the 11 January 1972 Boulder windstorm, Mon. Wea. Rev., 128, pp. 901-914.

Doyle, J. D, and Durran, D. R. (2003) Rotor dynamics in the lee of three-dimensional ridges, Orographic Flows Session, $10^{\text {th }}$ Conf. on Mesoscale Processes, AMS, Paper 11.4, 2 pages.

Grubišić, V., and Kuettner, J. P. (2004) Sierra rotors and the Terrain-induced Rotor Experiment (T-REX), $11^{\text {th }}$ Mountain Meteorology Conference, AMS, Paper 2.1, 7 pages.

Jiang, Q. F., and Doyle, J. D. (2003) Gravity wave breaking over the Central Alps: role of complex topography, 10th Conf. On Mesoscale Process., AMS, Paper 11.2, 4 pages.

Ludwig, F. L., Y. Chen, R. L. Street, 2002a: Integration of data from many sources for objective analysis of three-dimensional meteorological fields in the Salt Lake City Area, preprints 4th Symp. Urban Environ., Amer. Meteorol. Soc., Boston, pp 178-179.

Ludwig, F. L., R. Street, and Y. Chen, 2002b: Detection and interpretation of patterns of motion in mesoscale atmospheric flows, Eos, AGU Fall Meeting and Abstracts, CD, A51C-0068.

Ludwig, F. L., J. Horel, C. D. Whiteman, 2003: Using EOF analysis to identify important surface wind patterns in mountain valleys, J. Appl. Meteorol., 43, pp. 969-83.

Mesinger, F., Black, T. L., Plummer, D. W., and Ward, J. H. (1990) Eta model precipitation forecasts for a period including Tropical Storm Allison, Weather and Forecast, 5, pp. 483-493.

Oliker, L., Canning, A., Carter, J., Shalf, J., and Ethier, S. (2004) Scientific Computations on Modern Parallel Vector Systems, SC2004 High Performance Computing, Networking and Storage Conference; Pittsburg, PA; Nov 6 - 12., 12 pages, to appear.

Pielke, R. A., Cotton, W. R., Walko, R. L., Tremback, C. J., Lyons, W. A., Grasso, L. D., Nicholls, M. E. Moran, M. D., Wesley, D. A., Lee, T. J., and Copeland, J. H. (1992) A comprehensive meteorological modeling system -- RAMS, Meteor. Atmos. Phys., 49, pp. 6991.

Rao, P.A., Fueling, H. E., and Drogemeier, K. K. (1999) High-resolution modeling of the Cape Canaveral Area land-water circulations and associated features, Monthly Weather Review, 127, pp. 1808-1821. 
Ren, D. and M. Xue, 2004: A revised force-restore model for land-surface modeling. J. App. Meteor., in press.

Warner, T. T., Peterson, R. A., and Treadon, R. E. (1997) A tutorial on lateral boundary conditions as a basic and potentially serious limitation to regional numerical weather prediction, Bulletin AMS, 78, pp. 2599-2617.

Xue, M., Droegemeier, K., Wong, V., Shapiro, A., and Brewster, K. (1995) ARPS Version 4.0 User's Guide, Center for the Analysis and Prediction of Storms, U. Oklahoma.

Xue, M., D. H Wang, J. D. Gao, K. Brewster, and K. K. Droegemeier, (2003) The Advanced Regional Prediction System (ARPS), storm-scale numerical weather prediction and data assimilation, Meteor. Atmos. Phys., 82, pp. 139-170.

Xue, M., K. K. Droegemeier, and V. Wong, (2000) The Advanced Regional Prediction System (ARPS) - A multiscale nonhydrostatic atmospheric simulation and prediction tool. Part I: Model dynamics and verification, Meteor. Atmos. Phys., 75, pp. 161-193.

Xue, M., K. K. Droegemeier, V. Wong, A. Shapiro, K. Brewster, F. Carr, D. Weber, Y. Liu, and D. H. Wang, (2001) The Advanced Regional Prediction System (ARPS) - A multiscale nonhydrostatic atmospheric simulation and prediction tool. Part II: Model physics and applications, Meteor. Atmos. Phys., 76, pp. 134-165.

Zhong, S. and Fast, J. (2003) An evaluation of MM5, RAMS, and Meso Eta at subkilometer resolution using VTMX field campaign data in the Salt Lake Valley, Mon. Wea. Rev., 131, pp. 1301-1322. 